\title{
Challenges of Disorders of Sex Development: Diverse Perceptions across Stakeholders
}

\author{
Barry A. Kogan ${ }^{a} \quad$ Melissa Gardner ${ }^{b}$ Adrianne N. Alpern ${ }^{c}$ Laura M. Cohen ${ }^{c}$ \\ Mary Beth Grimley ${ }^{c}$ Alexandra L. Quittnerc David E. Sandberg ${ }^{\text {b }}$ \\ a Urological Institute of Northeastern New York and the Albany Medical College, Albany, N.Y., b University of \\ Michigan, Ann Arbor, Mich., and 'University of Miami, Miami, Fla., USA
}

\section{Key Words \\ Disorders of sex development - Health-related quality of life $\cdot$ Interdisciplinary teams $\cdot$ Pediatric urology $\cdot$ Pediatric endocrinology $\cdot$ Mental health professionals}

\begin{abstract}
Background/Aims: Disorders of sex development (DSD) are congenital conditions in which chromosomal, gonadal, or anatomic sex development is atypical. Optimal management is patient- and family-centered and delivered by interdisciplinary teams. The present pilot study elicits concerns held by important stakeholders on issues affecting young patients with DSD and their families. Methods: Content from focus groups with expert clinicians (pediatric urologists $(n=7)$, pediatric endocrinologists $(n=10)$, mental health professionals $(n=4)$, DSD patient advocates $(n=4)$, and interviews with parents of DSD-affected children (newborn to 6 years; $n=11$ ) was coded and content-analyzed to identify health-related quality of life issues. Results: Key stressors varied across stakeholder groups. In general, family-centered issues were noted more than child-centered. In the child-centered domain, providers worried more about physical functioning; family and advocates emphasized gender concerns and body image. In the family-centered domain,
\end{abstract}

parental concerns about medication management outweighed those of providers. Advocates reported more stressors regarding communication/information than other stakeholders. Conclusion: Variability exists across stakeholder groups in the key concerns affecting young children/ families with DSD. Interdisciplinary DSD healthcare team development should account for varying perspectives when counseling families and planning treatment.

Copyright $\odot 2012$ S. Karger AG, Base

\section{Introduction}

Disorders of sex development (DSD) are defined as congenital conditions in which development of chromosomal, gonadal or anatomic sex is atypical [1-4]. Medical and surgical recommendations for managing DSD have shifted over the past 50 years, in part because of a greater understanding of the process of psychosexual differentiation. At this juncture, a consensus statement has been issued by the Lawson Wilkins Pediatric Endocrine Society (renamed the Pediatric Endocrine Society in 2010) and the European Society for Paediatric Endocrinology, that calls for patient- and family-centered care delivered by an integrated, interdisciplinary team [4].

\section{KARGER}

Fax +4161306 1234

E-Mail karger@karger.ch

www.karger.com
(C) 2012 S. Karger AG, Basel

$1663-2818 / 12 / 0781-0040 \$ 38.00 / 0$

Accessible online at:

www.karger.com/hrp
Barry A. Kogan

Urological Institute of Northeastern New York and the Albany Medical College 23 Hackett Blvd.

Albany, NY 12208 (USA)

Tel. +1 518262 3296, E-Mail bkogan@ communitycare.com 
This optimal type of care requires that the differing perspectives of stakeholder groups (e.g. parents, health care providers) be understood. To date, only limited data examining the perspectives of parents of children with DSD exist $[5,6]$, and studies of DSD healthcare provider beliefs have, until now, not been conducted. Given this shift in care practices, systematic assessment of patient outcomes is necessary to evaluate whether these changes in care have produced positive effects. The purpose of this study was to identify key concerns affecting young children with DSD and their parents through in-depth, qualitative interviews with health care providers caring for patients with DSD (e.g. urologists, endocrinologists, mental health professionals), parents of young children with DSD, and advocates for this population.

The identification of key issues represents the first step in developing outcome measures that reflect how DSD affect the health-related quality of life (HRQoL) of patients and families. HRQoL is a multidimensional construct comprising several core dimensions (e.g. physical functioning and symptoms, psychological and emotional state, and social functioning), is patient/family, rather than physician-centered, and reflects subjective evaluations of daily functioning and psychological well-being [7, 8]. HRQoL measures are now frequently included in clinical trials [9], and are recommended as a key patient-reported outcomes (PROs) for chronic conditions [10]. In recent years, a consensus has emerged that disease/category-specific measures are more sensitive to 'smaller differences and smaller changes over time than generic measures [11]. Careful assessment of HRQoL measures in a variety of chronic diseases, such as cystic fibrosis, asthma, epilepsy, and cancer have all shown that disease/category-specific measures provide more precise measurement, more power to detect differences, and are more likely to lead to effective interventions $[2,3,8,12,13]$. There is an acute need for measures that describe how DSD affects the daily functioning of children and families, track the efficacy of new interventions or models of care, and identify strategies to improve care.

The present study elucidates, compares and contrasts the concerns held by important stakeholders regarding salient issues affecting patients with DSD and their families. In contrast to more quantitative methods, a qualitative approach [14], making use of interviews and focus groups with these stakeholders, was used to elicit critical stressors and concerns about DSD management that would provide the foundation for developing a HRQoL instrument.

Stakeholders' View of DSD

\section{Methods}

As a first step in the development of a HRQoL measure for children with DSD and their parents, we conducted a series of focus groups and interviews to identify the key issues for children and families with DSD. US and Canadian healthcare providers were selected to participate in telephone-based focus groups if they had substantial experience in the management of DSD, as evidenced by peer-reviewed publications on DSD, discipline-specific DSD committee work, and/or leadership responsibilities in their respective professional societies. Informed consent documents were mailed to 21 pediatric urologists, 22 pediatric endocrinologists, and 10 mental health providers; return rates were 48 , 59 and $60 \%$, respectively. There were no refusals and there were no discernible differences in professional experience or leadership responsibilities between those who returned informed consent vs. those who did not.

Due to scheduling conflicts, the numbers participating in the focus groups were as follows: 7 pediatric urologists, 10 pediatric endocrinologists and 4 mental health providers ( 2 pediatric psychologists, 1 social worker, and 1 psychiatrist). DSD patient advocates ( $\mathrm{n}=4 ; 1$ of whom is affected), were recruited for telephonebased focus groups from the leadership of US national advocacy/ parent support organizations. This stakeholder group included a leader of a national not-for-profit condition-specific organization, a parent of a DSD-affected child who organizes peer support events under the auspices of a second national not-for-profit organization for parents of children with chronic medical conditions, and two executive directors of DSD advocacy organizations. Finally, parents of young (newborn to 6 years) DSD-affected children were identified by medical chart review at one mid-west academic medical center. From a total eligible sample of 34 (based on diagnosis and/or phenotype), 24 households were targeted that adequately represented a range of ages, assigned gender, DSD diagnosis, and were located within one hour of the hospital to facilitate in-person focus groups. Six mothers and 5 fathers $(n=11)$ of 6 DSD-affected children participated. An additional 6 parents of 5 children were interested in participating but could not be scheduled conveniently for any of the three parent focus groups. Diagnostic and clinical management characteristics of the participating parents' children with DSD are summarized in table 1.

Interviews began with a primary question followed by several follow-up prompts (table 2). Focus groups were audiotaped and transcribed verbatim, with one exception. In that case, recording was not possible due to limitations of the facility; instead, responses were thoroughly documented via note-taking by one of the investigators (ALQ). Two groups of research staff independently performed a content analysis of the transcriptions and categorized the content into discrete areas of concern. Topics were categorized as either child- or parent/family-centered and grouped into domains. Sampling of content was judged complete when transcripts from later focus groups failed to generate new concerns (i.e. saturation of content was reached).

Data are presented in terms of the frequency with which each stakeholder group mentioned a specific concern. To adjust for differences in sample size between groups and length of transcripts, percentages of the total responses from each group within childand family-centered domains are presented (tables 3,4). To analyze whether there were substantive differences in the frequency of concerns mentioned both within and across stakeholder 
Table 1. Diagnostic and management characteristics of index children

\begin{tabular}{|c|c|c|c|c|c|c|}
\hline $\begin{array}{l}\text { Participating } \\
\text { parent }\end{array}$ & $\begin{array}{l}\text { Child } \\
\text { age }\end{array}$ & Child diagnosis & Child phenotype & \multicolumn{2}{|l|}{ Child gender } & $\begin{array}{l}\text { Number of child } \\
\text { genital surgeries }\end{array}$ \\
\hline $\begin{array}{l}\text { Mother } \\
\text { Father }\end{array}$ & 2 years & partial androgen insensitivity & $\begin{array}{l}\text { small phallus } \\
\text { bifurcated scrotum }\end{array}$ & girl & boy & 1 \\
\hline Mother & 2 years & $\begin{array}{l}\text { mixed gonadal dysgenesis } \\
(45, \mathrm{XO} / 46, \mathrm{XY})\end{array}$ & $\begin{array}{l}\text { penoscrotal hypospadias small } \\
\text { left testicle; absent right testicle }\end{array}$ & $\begin{array}{l}\text { delayed - ambiguous } \\
\text { genitalia }\end{array}$ & boy & 5 \\
\hline $\begin{array}{l}\text { Mother } \\
\text { Father }\end{array}$ & 11 months & 21-OH CAH & clitoromegaly & $\begin{array}{l}\text { delayed - ambiguous } \\
\text { genitalia }\end{array}$ & girl & 1 \\
\hline $\begin{array}{l}\text { Mother } \\
\text { Father }\end{array}$ & 4 years & $\begin{array}{l}\text { 46, XY hypospadias } \\
\text { (without molecular diagnosis) }\end{array}$ & penoscrotal hypospadias & girl & boy & 3 \\
\hline
\end{tabular}

Table 2. Focus group HRQoL questions ${ }^{1}$

\begin{tabular}{|c|c|}
\hline $\begin{array}{l}\text { HRQoL } \\
\text { dimension }\end{array}$ & Primary and exemplar follow-up questions \\
\hline $\begin{array}{l}\text { Physical } \\
\text { functioning }\end{array}$ & $\begin{array}{l}\text { In what ways does your child's medical condition } \\
\text { affect his or her activities? } \\
\text { Follow-up question: } \\
\text { - How does your child's medical condition affect } \\
\text { typical family routines? }\end{array}$ \\
\hline $\begin{array}{l}\text { Symptoms/ } \\
\text { treatment }\end{array}$ & $\begin{array}{l}\text { Tell me about your experiences and what you found/ } \\
\text { find stressful about your child's initial diagnosis and } \\
\text { their treatment } \\
\text { Follow-up question: } \\
\text { - What symptoms, or aspects of the treatment, bother } \\
\text { your child the most? }\end{array}$ \\
\hline $\begin{array}{l}\text { Psychological/ } \\
\text { social }\end{array}$ & $\begin{array}{l}\text { How do you think that your child's condition } \\
\text { (appearance, medical condition, parental discomfort } \\
\text { or anxiety) affects him or her emotionally? } \\
\text { Behaviorally? Educationally? Socially? } \\
\text { Follow-up question: } \\
\text { - Are you experiencing any problems with daycare/ } \\
\text { school/babysitters because of your child's condition } \\
\text { due to concerns about his or her physical appearance } \\
\text { including genital status, physical functioning, or } \\
\text { getting germs from other children? }\end{array}$ \\
\hline Other & $\begin{array}{l}\text { Selected examples: } \\
\text { - Was there any question at the birth about whether } \\
\text { you should raise your child as a boy or a girl? If so, } \\
\text { what was most difficult about this? } \\
\text { - Was it difficult informing your friends and family } \\
\text { - especially if you had expected a child of the other } \\
\text { sex because of ultrasounds? }\end{array}$ \\
\hline
\end{tabular}

\footnotetext{
${ }^{1}$ Questions are in the form used for parents; these received minor modifications to make them suitable for use with healthcare providers and advocates.
}

groups, discrepancies of $\geq 10 \%$ are discussed. A decision rule identifying discrepancies of $\geq 10 \%$ was adopted to maximize the information presented across stakeholders, while limiting the number of pairwise comparisons (38 comparisons using $\geq 5 \%$ rule vs. 7 comparisons for parents using the $\geq 10 \%$ rule).

Inter-Rater Agreement. Level of coding agreement, within each stakeholder group (e.g. urologist, parent), was calculated across all transcripts. Rates of agreement were calculated as a percentage of 'matches' on content categorization. Level of agreement ranged from 63 to $72 \%$, with a mean $66 \%$ agreement across informants.

The study was approved by the Institutional Review Board of the School of Medicine and Biomedical Sciences, University at Buffalo, Children and Youth Institutional Review Board, DB No. 936 .

\section{Results}

Content analysis of the focus groups and interviews revealed a wide range of concerns raised by these stakeholders. To facilitate analysis, the issues were divided into those focused on patients (child-centered; e.g. difficulty voiding) and those focused on families (family-centered; e.g. stress of remembering medications). Although a variety of issues were mentioned for both children and families, a greater number and more diverse array of concerns were mentioned in the family-centered domain. Overall, 29 unique concerns were mentioned for children and 97 for parents/families (tables 3, 4).

\section{Child-Centered Domains (table 3)}

Health care providers (i.e. urologists, endocrinologists, mental health professionals) endorsed more concerns (35-52\%) regarding 'Physical Functioning' than ad- 
Table 3. Child-centered domains with examples

\begin{tabular}{|c|c|c|c|c|c|}
\hline \multirow[t]{2}{*}{ Domains and most frequently endorsed topics } & \multicolumn{5}{|c|}{ Percentage of endorsement by stakeholder group } \\
\hline & $\begin{array}{l}\text { urologist } \\
(\mathrm{n}=7)\end{array}$ & $\begin{array}{l}\text { endocrinologist } \\
(\mathrm{n}=10)\end{array}$ & $\begin{array}{l}\text { mental health } \\
(\mathrm{n}=4)\end{array}$ & $\begin{array}{l}\text { advocate } \\
(\mathrm{n}=4)\end{array}$ & $\begin{array}{l}\text { parent } \\
(\mathrm{n}=11)\end{array}$ \\
\hline $\begin{array}{l}\text { Physical functioning ( } 7 \text { topics) } \\
\text { Pressures/stress/anxiety for boys who cannot stand to urinate } \\
\text { Difficulty voiding }\end{array}$ & 52 & 35 & 48 & 20 & 22 \\
\hline $\begin{array}{l}\text { Gender concerns/body image ( } 9 \text { topics) } \\
\text { Child cannot identify with the same sex (they are a girl but feel like a boy) } \\
\text { Confusion about genital appearance and gender (e.g. I am a girl, but look like a boy) }\end{array}$ & 9 & 26 & 10 & 37 & 22 \\
\hline $\begin{array}{l}\text { Social functioning ( } 5 \text { topics) } \\
\text { Social difficulties } \\
\text { Child's condition limiting social activities }\end{array}$ & 4 & 13 & 3 & 20 & 13 \\
\hline $\begin{array}{l}\text { Emotional functioning ( } 1 \text { topic) } \\
\text { Child questioning why they are different; trying to understand the disorder }\end{array}$ & 0 & 0 & 0 & 0 & 4 \\
\hline $\begin{array}{l}\text { Medications and procedures ( } 7 \text { topics) } \\
\text { Stress/embarrassment of genital exams (inappropriate exclusive focus on genitals) } \\
\text { Repeated and/or painful medical procedures (e.g. blood draws, hormone shots, gonadal } \\
\text { biopsies, vaginoplasty) }\end{array}$ & 35 & 26 & 38 & 23 & 39 \\
\hline Total topics (frequency) & 23 & 23 & 29 & 30 & 23 \\
\hline
\end{tabular}

vocates $(20 \%)$ and parents $(22 \%)$. In contrast, advocates (37\%), endocrinologists (26\%) and parents (22\%) focused more on 'gender concerns and body image' than urologists (9\%) and mental health professionals (10\%). Further, urologists, mental health professionals, and parents endorsed more concerns about 'medications and procedures' (range 35-39\%) than advocates (23\%); parents reported more concerns in this domain (range 38-39\%) than endocrinologists (26\%).

\section{Parent/Family-Centered Domains (table 4)}

More concerns were mentioned that were coded as falling in the family-centered domain and these were spread over a wider range of domains and topics (table 4); accordingly, the percentage of concerns falling within specific domains was smaller. Parents' predominant concerns fell into the domains of 'diagnosis', 'medical management', 'communication/information', and 'future worries' (14-22\%). In contrast, endocrinologists, mental health professionals, and advocates endorsed medical management concerns less often (5-10\%) than parents (22\%). Endocrinologists and advocates emphasized:

'Communication/information' (17 and 23\%, respectively) and Future Worries (17 and 12\%) issues; for both stakeholder groups, these were two most frequently mentioned areas of concern. Notably, endocrinologists reported more 'Gender Concerns' (12\%) than parents (2\%).

\section{Discussion}

We found general agreement among health care providers about the major concerns faced by children with DSD and their families; however, there were significant differences between the stakeholder groups. All stakeholders were concerned that experiences such as repeated genital exams and painful medical procedures might exert negative effects on children, including self-consciousness about their condition. Limiting the number of these exams/interventions, determining when they are necessary, and utilizing strategies to reduce the potential negative psychological sequelae are important implications of these findings. Incorporating behavioral health clinicians (e.g. psychologists or child life specialists) who have expertise in preparing children for medical procedures (e.g. desensitization to needles and/or genital exams) could be very useful in the care of children with DSD. These providers can promote effective coping through medical play, preparation, and education.

The health care provider stakeholders focused more concern over physical functioning (especially urinary voiding) than did parents and advocates. This information is of particular importance to urologists who, in large part, look to parents' expectations as an indication of whether surgery is warranted. 
Table 4. Parent/family-centered domains with examples

Domains and most frequently endorsed topics

Decision making (7 topics)

Lack, or ambiguity, of information on which to base decisions

Concern about the irreversible nature of decisions
Role functioning and family activities (10 topics)

Concerns about locating good child care

Concerned and sometimes upset about how the child voids/changing diapers

Anatomy and voiding (2 topics)

Power struggles over voiding

Concerned or upset about how the child voids

Gender concerns (8 topics)

Parental disagreement over gender assignment (with extended family, healthcare

professionals)

Worry about gender identification (gender appropriate toys/playmates)

Appearance (3 topics)

Appearance of genitalia

Upset over the child's genital ambiguity

Social functioning (8 topics)

Wanting to talk to other parents in similar situations

Cultural beliefs and pressures regarding care/clinical management

Emotional functioning (8 topics)

Feeling protective of child

Fear of child's death

Future worries (9 topics)

Concerns over children's future fertility

Worry over long-term surgical outcomes

Communication/information (12 topics)

Managing communication with healthcare professionals (pressure, misleading information)

Stress of navigating conflicting medical information (healthcare professionals, internet)

Disclosure (6 topics)

Difficulty telling family and friends about the condition

Having to explain the condition, or why they are different to their child

Medical management (12 topics)

Making sure the child is getting the appropriate medications at the right time

Stress of remembering medications

Diagnosis (12 topics)

Stress of uncertain diagnosis and treatment; waiting for the diagnosis

Emotionally overwhelmed upon receiving diagnosis (stress, anxiety)

Total topics (frequencies)

)

Percentage of endorsement by stakeholder group

urologist endocrinol- mental health advocate parent

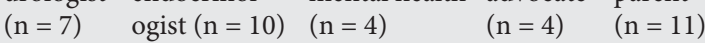

$\begin{array}{lllll}4 & 6 & 2 & 9 & 2\end{array}$

14

6

8

9

10

2

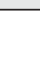


16] to facilitate adherence to the treatment regimen. Education and ongoing support for dealing with the challenges of medication adherence have proven helpful.

For the advocates, concerns over communication/information dominated other topics categorized as parent/ family-centered ( $23 \%$ of 136 comments), although the other stakeholder groups also considered this a stressor (9-17\%). It is possible that advocates were recalling an era of care for persons with DSD characterized by limited disclosure of diagnostic and other medical/surgical information to patients and, occasionally, even parents [1719]. The consensus statement on DSD [4] underscores the importance of transparent communication of diagnostic and procedural information with parents, along with developmentally sensitive education of patients. Although the knowledge base regarding the etiology of DSD has expanded and communication practices may have improved, this is an area that continues to be challenging. As in other chronic conditions, a comprehensive understanding of the condition is a necessary prerequisite for shared decision-making and patient/family-centered care.

In general, more parent/family- than child-centered concerns were raised. Given that children in this age range could not be directly interviewed, we may not have adequately captured the child's own perspective. It is also likely that children in this age group (less than 7 years) experience the DSD and its management as less of an issue than their parents. Their perceptions of the influence of their condition on daily life may change with age as there is a progressive developmental shift towards peers and social interactions outside the family. We are planning a study of affected school-age children to directly assess their issues and concerns.

The differences observed among stakeholders in this study have potentially important consequences for clinical care. As we move from an era of physician-driven to patient/family-centered care and shared decision-making, it will be important for DSD specialists to consider not only the viewpoints of patients (and, in the case of young children, their parents) but also the varying perspectives of health care providers involved in caring for these children [20]. The current focus on systematically assessing patient-reported outcomes is one mechanism for achieving a greater understanding of patient and family views and preferences $[7,8]$. The development of HRQoL measures for parents of young children with DSD would be ideal for systematically identifying parental concerns as they arise during the course of clinical management [21].
The diversity of perspectives of those involved in caring for newborns and young children with DSD highlights the need for strong channels of communication among members of the DSD healthcare team and between the team and family. Indeed, as different health professionals direct patient care priorities, it would behoove them to be aware of the opinions of other stakeholders. As noted in several recently published papers on the management of DSD [22-24], the goal is to develop tightly coordinated and integrated services that emphasize clear communication with the family, rather than simply offering services at the same location.

One limitation of this study is the somewhat wide age range (children were 11 months to 6 years). Our goal was to focus on young children, but recognize that even in this group there will be a range of issues that may be more prominently remembered at certain time points. For example, issues around surgery may much more be vivid for parents of children around a year of age and much less so for those parents whose children are older. For the most part, this limitation would apply primarily to the parent group.

This study is qualitative which, by its nature, employs in-depth interviews with small samples. Nonrandom sampling is guided by selection of participants most likely to yield insights into the phenomenon under investigation $[14,25]$. Healthcare providers and advocates were selected for this study because of their depth of experience in managing the medical/surgical care of affected persons and, especially in the case of advocates, communicating/advocating on patients' behalf. Of note, these participants were not randomly selected. Similarly, we interviewed 11 parents of 6 young children with DSD who were otherwise healthy and who represented a range of DSD diagnoses. Note that specific parental concerns may vary based on the heterogeneity of these conditions and their impact, but we aimed to include as diverse a sample as possible. Related primarily to the focus on the age range of 11 months to 6 years, only one affected patient was included (a member of the advocate group). We are in the process of conducting a multisite study involving a large sample of patients with DSD and their families using a newly developed HRQoL measure that focus on issues specific to, and shared by, young patients with DSD and their families [21]. This larger study will allow us to test the generalizability of the parental concerns documented here and determine the degree to which distinct diagnoses (e.g. CAH) are associated with specific stressors and concerns. 


\section{Conclusion}

We found that concerns related to the diagnosis and management of DSD varied according to stakeholder group: health care specialists, advocates, or parents. These results highlighted the importance of seeking the full range of informed perspectives, especially those of parents of young DSD-affected children. The primary role of an integrated, interdisciplinary team would be to assess all of these perspectives and provide care that is founded on a patient- and family-centered model.

\section{Acknowledgements}

This project was supported in partby Award No. R21HD044398 and R01HD053637 from the Eunice Kennedy Shriver National Institute of Child Health and Human Development and by the Capital Region Medical Research Foundation. The content is solely the responsibility of the authors and does not necessarily represent the official views of the Eunice Kennedy Shriver National Institute of Child Health and Human Development or the National Institutes of Health or the Capital Region Medical Research Foundation. The authors thank the healthcare providers, patient advocates, and parents who participated in the focus groups. We also thank Erica Eugster, MD, for assistance in recruiting participating parents and the research staff who assisted in coding the transcripts, including Cheryl Twaragowski and Lolita Ontiveros.

\section{References}

1 Sanders C, Carter B, Goodacre L: Parents' narratives about their experiences of their child's reconstructive genital surgeries for ambiguous genitalia. J Clin Nurs 2008; 17 : 3187-3195.

-2 Juniper EF, Guyatt GH, Feeny DH, Ferrie PJ, Griffith LE, Townsend M: Measuring quality of life in children with asthma. Qual Life Res 1996;5:35-46.

3 Osaba D, Hsu M, Copley C, et al: Stated preferences of patients with cancer for healthrelated quality of life (HRQOL) domains during treatment. Qual Life Res 2005;15: 273-283.

4 Lee PA, Houk CP, Ahmed SF, Hughes IA; in collaboration with the participants in the International Consensus Conference on Intersex: consensus statement on management of intersex disorders. Pediatrics 2006;118: e488-e500.

5 Dayner JE, Lee PA, Houk CP: Medical treatment of intersex: parental perspectives. J Urol 2004; 172:1762-1765.

6 MacKenzie D, Huntington A, Gilmour JA: The experiences of people with an intersex condition: a journey from silence to voice. J Clin Nurs 2009; 18:1775-1783.

7 Fayers P, Hays R (eds): Assessing Quality of Life in Clinical Trials, ed 2. New York, Oxford University Press, 2005.

8 Quittner AL, Cruz I, Modi AC, Marciel KK: Health-related quality of life instruments for adolescents with chronic diseases; in O'Donohue WT, Tolle LW (eds): Behavioral Approaches to Chronic Disease in Adolescence. New York, Springer, 2009, pp 311327.

$\checkmark 9$ US Department of Health Human Services FDA Center for Drug Evaluation Research, US Department of Health Human Services FDA Center for Biologics Evaluation and Research, US Department of Health Human
Services FDA Center for Devices and Radiological Health: Guidance for industry: patient-reported outcome measures. Use in medical product development to support labeling claims: draft guidance. Health Qual Life Outcomes 2006;4:79.

10 Palermo TM, Long AC, Lewandowski AS, Drotar D, Quittner AL, Walker LS: Evidence-based assessment of health-related quality of life and functional impairment in pediatric psychology. J Pediatr Psychol 2008; 33:983-996.

11 Hays R: Generic versus disease-targeted instruments; in Fayers P, Hays R (eds): Assessing quality of life in clinical trials. New York: Oxford University Press 2005, pp 3-8.

12 Birbeck GL, Kim S, Hays RD, Vickery BG: Seizure reduction and quality of life improvements in people with epilepsy. Epilepsia 2002;43:535-538.

13 Quittner AL, Davis MA, Modi AC: Healthrelated quality of life in pediatric populations; in Roberts MC (ed): Handbook of Pediatric Psychology. New York, Guilford Press, 2003, pp 696-709.

14 Creswell JW: Qualitative Inquiry and Research Design. Thousand Oaks, Sage Publications, 2007.

15 Marciel KK, Saiman L, Quittell LM, Dawkins $\mathrm{K}$, Quittner AL: Cell phone intervention to improve adherence: cystic fibrosis care team, patient, and parent perspectives. Pediatr Pulmonol 2010;45:157-164.

16 Quittner AL, Modi AC, Lemanek KL, IeversLandis CE, Rapoff MA: Evidence-based assessment of adherence to medical treatments in pediatric psychology. J Pediatr Psychol 2008;33:916-936.

17 Daaboul J, Frader J: Ethics and the management of the patient with intersex: a middle way. J Pediatr Endocrinol Metab 2001;14: 1575-1583.
18 Frader J, Alderson P, Asch A, et al: Health care professionals and intersex conditions. Arch Pediatr Adolesc Med 2004;158:426428

19 Chase C: What is the agenda of the intersex patient advocacy movement? Endocrinologist 2003;13:240-242.

20 Meyer-Bahlburg HFL: Treatment guidelines for children with disorders of sex development. Neuropsychiatr Enfance Adolesc 2008; 56:345-349.

21 Sandberg D, Gardner M, Kogan B, et al: Assessing health-related quality of life in disorders of sex development: phase I - item generation; in New M, Simpson J (eds): Hormonal and Genetic Basis of Sexual Differentiation Disorders and Hot Topics in Endocrinology. Proc 2nd World Conference, Advances in Experimental Medicine and Biology 707. New York, Springer Science+Business Media, 2011, pp 143-146.

22 Auchus R, Witchel S, Leight K, et al: Guidelines for the development of comprehensive care centers for congenital adrenal hyperplasia: guidance from the cares foundation initiative. Int J Pediatr Endocrinol 2010;2010: 275213. Epub 2011 Jan 10.

23 Douglas G, Axelrad M, Brandt M, et al: Consensus in guidelines for evaluation of DSD by the Texas Children's Hospital multidisciplinary gender medicine team. Int J Pediatr Endocrinol 2010;2010:919707.

24 Schaeffer T, Tryggestad J, Mallappa A, et al: An evidence-based model of multidisciplinary care for patients and families affected by classical congenital adrenal hyperplasia due to 21-hydroxylase deficiency. Int J Pediatr Endocrinol 2010;2010:692439.

25 Kazdin AE: Research Design in Clinical Psychology. Boston, Allyn \& Bacon, 2003. 